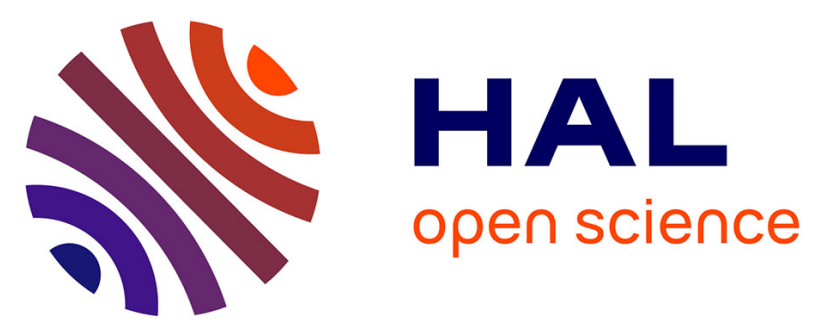

\title{
Online self-sampling kits to screen multipartner MSM for HIV and other STIs: Participant characteristics and factors associated with kit use in the first three months of the MemoDepistages program, France, 2018
}

Delphine Rahib, Héloïse Delagreverie, Audrey Gabassi, Thuy Le Thi, Eléonore Vassel, Pierre Vodosin, Benjamin Leveau, Amandine Pisoni, Edouard Tuaillon, Julien Digne, et al.

\section{- To cite this version:}

Delphine Rahib, Héloïse Delagreverie, Audrey Gabassi, Thuy Le Thi, Eléonore Vassel, et al.. Online self-sampling kits to screen multipartner MSM for HIV and other STIs: Participant characteristics and factors associated with kit use in the first three months of the MemoDepistages program, France, 2018. Sexually Transmitted Infections, 2021, 10.1136/sextrans-2020-054790 . hal-03274494

\section{HAL Id: hal-03274494 \\ https://hal.sorbonne-universite.fr/hal-03274494}

Submitted on 30 Jun 2021

HAL is a multi-disciplinary open access archive for the deposit and dissemination of scientific research documents, whether they are published or not. The documents may come from teaching and research institutions in France or abroad, or from public or private research centers.
L'archive ouverte pluridisciplinaire HAL, est destinée au dépôt et à la diffusion de documents scientifiques de niveau recherche, publiés ou non, émanant des établissements d'enseignement et de recherche français ou étrangers, des laboratoires publics ou privés. 
Online self-sampling kits to screen multipartner MSM for HIV and other STIs: Participant characteristics and factors associated with kit use in the first three months of the MemoDepistages program, France, 2018

Delphine Rahib ${ }^{1,2}$ (delphine.rahib@santepubliquefrance.fr), Héloïse Delagreverie ${ }^{3}$, Audrey Gabassi ${ }^{3}$,ThanThuy Le Thi ${ }^{4}$, Eléonore Vassel ${ }^{4}$, Pierre Vodosin ${ }^{4}$, Benjamin Leveau ${ }^{4}$, Amandine Pisoni ${ }^{6}$, Edouard Tuaillon ${ }^{6}$ Julien Digne ${ }^{5}$, Vinca Icard 4 , Constance Delaugerre ${ }^{3}$, Nathalie Lydié ${ }^{1}$ pour le groupe MémoDépistages 1 Santé publique France, Saint Maurice, France

2 UPMC Université Paris 6, Inserm, Institut Pierre Louis d'Épidémiologie et de Santé Publique (IPLESP UMRS 1136), Paris, France

3 Laboratoire de Virologie, Hôpital Saint Louis, APHP, Inserm U944, Université de Paris, France

4 Hospices civils de Lyon, Hôpital de la Croix-Rousse, Centre de ressources biologiques Nord, Lyon, France 5 Laboratoire Alphabio, Marseille, France

6 Département de bactériologie-virologie, CHU de Montpellier, UMR Inserm 1058, Université de Montpellier, France

\section{Corresponding author:}

\section{Delphine Rahib,}

Agence nationale de santé publique, Santé Publique France

12 , rue du val d'Osne

94415 Saint Maurice cedex

delphine.rahib@santepubliquefrance.fr

$+33(0) 171801592$

Co-authors :

Héloïse Delagreverie, Audrey Gabassi \& Constance Delaugerre : Laboratoire de Virologie, Hôpital Saint Louis, APHP, 1 avenue Claude Vellefaux, 75010 Paris, France

Than-Thuy Le Thi, Eléonore Vassel, Pierre Vodosin, Benjamin Leveau \& Vinca Icard : Hospices civils de Lyon, Hôpital de la Croix-Rousse, Centre de ressources biologiques Nord, 103 grande rue de la Croix Rousse, 69004 Lyon, France

Julien Digne : Laboratoire Alphabio, 1 rue Melchior Guinot, 13003 Marseille, France

Amandine Pisoni \& Edouard Tuaillon : Département de bactériologie-virologie, CHU de Montpellier, 7, avenue du Doyen Gaston Giraud - 34295 MONTPELLIER Cedex 5, France

\section{Contribution :}

DR \& NL conceptualised and managed the study, HD, CD, TTLT, VI, JD \& ET contributed to the study design, DR, HD, AG, EV, PV, BL \& AP managed the data collection, DR cured, analysed and interpreted the data to wrote the first full draft of the manuscript, NL \& HD provided intellectual input for interpretation and reviewed first draft of the manuscript.

Keywords : Screening, Service delivery, men

Word Count : 3091 
Online self-sampling kits to screen multipartner MSM for HIV and other STIs: Participant characteristics and factors associated with kit use in the first three months of the MemoDepistages program, France, 2018

Abstract (298/300)

Objectives: In 2017, to reduce the proportion of MSM in the undiagnosed HIV population in France $(38 \%)$, HIV screening is advise each three months and sexually transmitted infection (STI) screening is advise each year in multipartner men who have sex with men (MSM). Despite the range of testing solutions, over $40 \%$ of MSM were not tested for HIV and over $50 \%$ for STIs in the past year. Based on international experiments that offer screening solutions via online advertising, the French National Health Agency launched a program (MemoDepistages) to provide a free self-sampling kit (SSK) for HIV and STIs. This article analyses the sociodemographic and behavioral characteristics of MSM in terms of kit acceptance and sample return.

Methods: Participants registered for the program online after ordering a SSK. The study included men aged over 18 years, living in one of the four selected French regions, and willing to disclose their postal and email address; they had health insurance, acknowledged more than one male partner in the past year, indicated a seronegative or unknown HIV status, and were not taking medically prescribed preexposure prophylaxis drugs. Samples were collected by users and posted directly to the laboratory. Characteristics associated with kit acceptance and sample return were analyzed using logistic regression.

Results: Overall, 7,158 eligible MSM were offered to participate in the program, with 3,428 ordering the kit (47.9\%) and 1,948 returning their sample, leading to a return rate of $56.8 \%$ and an overall participation rate of $27.2 \%$. Acceptance and return rates were strongly associated with sociodemographic characteristics, mainly education level but not with behavioral characteristics. Non-college graduates had lower acceptance $(44.2 \%)$ and return rates $(47.7 \%)$.

Conclusion: The program rapidly recruited a large number of MSM. It removed geographical inequalities related to screening access. 


\section{Introduction}

In France, the population of men who have sex with men (MSM) is the most affected by HIV and sexually transmitted infections (STIs). In 2017, they had the highest undiagnosed HIV prevalence in the country [1], while the number of STI cases in this population has increased for several years. To reverse this trend, the French Haute autorite de santé recommended quarterly HIV screening in high-risk MSM [2]. This strategy is based on a wide range of testing solutions: in addition to reimbursed laboratory tests and free testing in sexual health clinics, rapid HIV tests can be performed by family practitioners and trained non-governmental organizations. In September 2015, a blood-based HIV self-test was approved for over-thecounter sales, and among MSM tested in 2017, 5\% used it for their last screening [3]. Despite this wide range of solutions, in 2017 , only $53 \%$ of MSM were tested for HIV in the past 12 months, while very few $(15 \%)$ had used three or more tests [4].

At the time of this study, no national guidelines were in place for a global approach to STI testing in MSM. However, the French Society of Dermatology recommended for sexually active MSM to be tested annually for syphilis, hepatitis C (HCV), as well as Chlamydia trachomatis $(\mathrm{Ct})$ and Neisseria gonorrhea $(\mathrm{Ng})$ in pharyngeal, urine, and anal samples [5]. Hepatitis $\mathrm{B}$ (HBV) should also be tested, with vaccination proposed depending on the result. STI testing options are limited in comparison to those for HIV. Tests are available at sexual health clinics or laboratories on prescription. Rapid testing performed by non-governmental organizations has existed for HCV since 2016. Currently, however, there is no self-managed solution for STI screening comparable to the HIV self-test in France. The screening rates for STIs are poorer than those for HIV. For example, in $2017,46.4 \%$ of sexually active MSM were screened for $\mathrm{HCV}, 43.6 \%$ for syphilis, $36.3 \%$ for $\mathrm{Ct}$, and $32.5 \%$ for $\mathrm{Ng}$ during the past 12 months (Personal communication, Eras Study [6])

To meet the new French guidelines and increase the frequency of HIV and STI testing among MSM, there is a need to develop novel approaches and engage MSM where testing was not already offered. Novel outreach design needs to be conceived for modern dating approaches such as dating apps. Using online communities, services can now offer self-sampling kits (SSKs) for HIV screening to key populations through distance facilities [7] Since 2016, the UK has provided a national home SSK service free of charge [8]. Several studies have analyzed the factors associated with HIV SSKs use, showing that users have a higher education level, better income, and are younger [7,9] than those who do not use it. Compared to heterosexual men, MSM also tend to be more willing to use such services [7,9-15]. Most SSKs propose blood sampling for HIV screening or local sampling for $\mathrm{Ct} / \mathrm{Ng}$ screening. Only a few propose both types of sampling in the same kit to detect both viral and bacterial infections.[7]

Building on the results from these projects, the French public health agency developed the MemoDepistages program. With an 18-month follow-up, this program aims at increasing quarterly testing among multipartner MSM recruited trough dating apps and targeted websites. It offers a SSK for HIV, HBV, HCV, syphilis, Ct, and $\mathrm{Ng}$ screening. The SSK included a microtainer tube and two finger prick tests for blood collection, a uriswab device to collect urine, and two swabs and PCR-compatible medium for anal and pharyngeal samples. To our knowledge, this was the most comprehensive STI self-sampling kit described in international studies.

To date, few studies have explored the step-by-step process of screening using these services: participants first needs to subscribe to the service, perform the self-sampling, and then send it 
to the laboratory. This article analyzes the different factors that impact the overall participation in the first screening round of the program.

\section{Method}

\section{Study population}

Men were recruited between April 11 $1^{\text {th }}, 2018$ and June $10^{\text {th }}, 2018$ through targeted online advertisement, MSM sex apps and community websites. Geolocated advertisements redirected viewers to a 5-minute questionnaire investigating the sociodemographic and behavioral characteristics of MSM and verifying their eligibility. Eligibility criteria were as follows: males over 18 years, living in one of the four French regions with the highest HIV prevalence [1] (Auvergne Rhone Alpes, Ile de France, Occitanie Est, and Provence Alpes Côte d'Azur), and willing to disclose their postal and email address; they acknowledged more than one male partner during the past year, indicated a seronegative or unknown HIV status. Men using PrEP with prescription were excluded from the study because an appointment with their practitioner every three months was mandatory for PrEP prescription. They benefited from a STI screening during this consultation. However, men who used PrEP without any medical follow-up could be recruited. According to French regulation on biomedical research, only participants who declare to be affiliated to the national health insurance have been recruited. The protocol was approved by local authorities under the number ID RCB 2017-A00838-45 and ethics committee CPP-Ouest II-ANGERS.

\section{Definitions and measures}

Eligible men were offered to participate in the MemoDépistages program, in which case an STI SSK would be sent to them within 24 hours. Those who accepted to participate in the program and ordered the kit are referred to as subscribers. The acceptance rate was defined as the proportion of subscribers out of eligible men.

They collected their samples and sent them to the laboratory in a prepaid envelope. The men who sent at least one sample to the laboratory before September $1^{\text {st }}, 2018$ are referred to as participants. The return rate was thus defined as the proportion of participants out of subscribers.

The overall participation rate was defined as the proportion of participants among eligible men. (Fig.1)

\section{Statistical analyses}

Statistical analyses were performed using Stata $v 14^{1}$. As data were collected online using an automatic completeness check, there were no missing data in the dataset. Sociodemographic and behavioral characteristics associated with men's acceptance and return of the kit were tested using a Khi ${ }^{2}$ test. Since Stata v14 treats collinearity in models, and the number of events was more than 10 times the sum of all the terms of interest, variables with a $p$ coefficient equal to or less than 0.2 were considered for integration and interpreted in the logistic regression. Possible interactions between independent characteristics were tested by including crossproduct terms in the regression, with $p<0.05$ deemed to be indicative of statistical significance. Significant interaction terms included in the final model are presented in the tables.

\footnotetext{
${ }^{1}$ StataCorp. 2015. Stata Statistical Software: Release 14. College Station, TX: StataCorp LP.
} 


\section{Results}

Over the 2 months of the recruitment period, 12,758 questionnaires were completed. The screening program and kit were offered to 7,158 eligible men $(56.1 \%)$. The acceptance rate was $47.9 \%$ with 3,428 subscribers. Among them, 1,948 participants sent samples to the laboratories, leading to a return rate of $56.8 \%$ and an overall participation rate of $27.2 \%$.

\section{$\underline{\text { Description of eligible men }}$}

The main reason for ineligibility was not living in one of the four regions of the study $(60.6 \%)$, followed by having only one male partner during the past year (16.9\%).

The median age of eligible men was 31 years. (Table 1). A majority $(68.7 \%)$ had a collegelevel education, lived in a large city of more than 100,000 inhabitants $(52.1 \%)$, and considered their financial situation to be good or average (82.1\%). In terms of sexual behavior, $68.1 \%$ of participants had more than five partners in the past year, and most had their last intercourse with a non-steady partner $(78.5 \%)$. Nearly one out of four $(21.2 \%)$ eligible men had never visited a gay meeting place (i.e., bar, club, sauna with or without sex, outdoor gay sex venue). In terms of HIV prevention, $44.1 \%$ did not use protection - i.e., condoms, pre-exposure prophylaxis, or treatment as prevention - during their last sexual intercourse, including $38.6 \%$ whose last intercourse was with a non-steady partner. Half the eligible men $(49.3 \%)$ were tested for HIV in the last 12 months, half of them being tested several times. Screening for $\mathrm{Ct}$ and $\mathrm{Ng}$ was less frequent, with $29.1 \%$ of eligible participants reporting a urinal or urethral test, $13.0 \%$ a pharyngeal test, and $11.5 \%$ an anal test over the past year.

Acceptance rate and associated factors

The acceptance rate ranged from $41.3 \%$ to $51.7 \%$ depending on the sociodemographic and behavioural characteristics (Table 2). 
Table 1. Sociodemographic characteristics of men offered to participate in the MemoDépistages program, 2018 $(n=7,158)$

\begin{tabular}{|c|c|c|}
\hline $\begin{array}{l}\text { Age } \\
\text { Median (interquartile range) }\end{array}$ & $\mathrm{n}$ & $\begin{array}{r}\% \\
\text { years } \\
\end{array}$ \\
\hline \multicolumn{3}{|l|}{ Born in France } \\
\hline Yes & 6,549 & 91.5 \\
\hline No & 609 & 8.5 \\
\hline \multicolumn{3}{|l|}{ Education } \\
\hline High school or less & 2,242 & 31.3 \\
\hline College or more & 4,916 & 68.7 \\
\hline \multicolumn{3}{|l|}{ Perceived financial situation } \\
\hline Good & 3,342 & 46.7 \\
\hline Average & 2,534 & 35.4 \\
\hline Bad & 1,281 & 17.9 \\
\hline \multicolumn{3}{|l|}{ Area of residence } \\
\hline Less than 2,000 inhabitants & 380 & 5.3 \\
\hline Between 2,000 and 19,999 inhabitants & 1,277 & 17.8 \\
\hline Between 20,000 and 99,999 inhabitants & 1,775 & 24.8 \\
\hline More than 100,000 inhabitants & 3,726 & 52.1 \\
\hline \multicolumn{3}{|l|}{ Region } \\
\hline Paris area & 4,220 & 59.0 \\
\hline Auvergne Rhône Alpes & 1,525 & 21.3 \\
\hline Provence Alpes Côte d'Azur & 867 & 12.1 \\
\hline Occitanie & 546 & 7.6 \\
\hline \multicolumn{3}{|c|}{ Frequenting gay meeting places (with or without sex) } \\
\hline Often & 1,974 & 27.6 \\
\hline Sometimes & 3,669 & 51.3 \\
\hline Never & 1,515 & 21.2 \\
\hline \multicolumn{3}{|l|}{ Previous HIV tests } \\
\hline Several times in the past 12 months & 1,838 & 25.7 \\
\hline Once in the past 12 months & 1,686 & 23.6 \\
\hline At least once more than 12 months ago & 2,791 & 39.0 \\
\hline None & 843 & 11.8 \\
\hline \multicolumn{3}{|l|}{$\begin{array}{l}\text { Previous } \mathrm{Ct} / \mathrm{Ng} \text { test in the past } 12 \\
\text { months } \$\end{array}$} \\
\hline Urinal/urethral & 2,085 & 29.1 \\
\hline Pharyngeal & 933 & 13.0 \\
\hline Anal & 826 & 11.5 \\
\hline \multicolumn{3}{|c|}{ Number of male sexual partners in the past 12 months } \\
\hline $2-5$ & 2,283 & 31.9 \\
\hline $6-10$ & 1,918 & 26.8 \\
\hline $11-20$ & 1,507 & 21.1 \\
\hline$>20$ & 1,450 & 20.3 \\
\hline \multicolumn{3}{|l|}{ Last partner } \\
\hline Steady & 1,540 & 21.5 \\
\hline Casual & 5,618 & 78.5 \\
\hline \multicolumn{3}{|l|}{ Protection at last intercourse $\$$} \\
\hline Condom & 3,817 & 53.3 \\
\hline Treatment as prevention & 57 & 0.8 \\
\hline Pre-exposure prophylaxis & 193 & 2.7 \\
\hline None & 3,155 & 44.1 \\
\hline
\end{tabular}

*protection against HIV (i.e., condom, treatment as prevention, pre-exposure prophylaxis)

\$ Total is different from $100 \%$. Multiple answers could apply 
Table 2. Association between sociodemographic and behavioral factors and overall participation in MemoDépistages first screening, 2018 ( $n=7,158$ )

Age

Under 30 years

30 years and over

$p$

\section{Born in France}

Yes

No

$p$

Level of education

High school or less

College or more

\section{Perceived financial situation}

Good

Average

$\mathrm{Bad}$

$p$

Area of residence

Less than 2,000 inhabitants

Between 2,000 and 19,999 inhabitants

Between 20,000 and 99,999 inhabitants

More than 100,000 inhabitants

$p$

Region

Paris area

Auvergne Rhône Alpes

Provence Alpes Côte d'Azur

Occitanie

\section{OVERALL PARTICIPATION}$$
\text { N }
$$

$n$

$\%$ ORa

p $\quad I C 95 \%$

$\begin{array}{rrrcrr}3,082 & 897 & 29.1 & \text { Ref } & \\ 4,076 & 1,051 & 25.8 & 0.83<10^{-3} & (0.74-0.92) \\ & & 0.002 & & & \end{array}$

6,549

$\begin{array}{rrrrr}1,766 & 27.0 & \text { Ref } & & \\ 182 & 29.9 & 1.07 & 0.475 & (0.89-1.29)\end{array}$

$2,242 \quad 472 \quad 21.1 \quad 0.66<10^{-3} \quad(0.58-0.75)$

4,916

$1,476 \quad 30.0 \quad$ Ref

$<10-$

3,342

2,534

1,281

\section{$\begin{array}{lll}928 & 27.8 \quad \text { Ref }\end{array}$}

$\begin{array}{lllll}709 & 28.0 & 1.05 & 0.408 & (0.93-1.18)\end{array}$

$\begin{array}{lllll}311 & 24.3 & 0.91 & 0.229 & (0.78-1.06)\end{array}$

0.033

$\begin{array}{llllll}380 & 96 & 25.3 & 0.99 & 0.938 & (0.77-1.27)\end{array}$

$\begin{array}{lllllll}1,277 & 312 & 24.4 & 0.93 & 0.355 & (0.80-1.08)\end{array}$

$\begin{array}{lllllll}1,775 & 464 & 26.1 & 0.97 & 0.632 & (0.85-1.10)\end{array}$

3,726

$1,076 \quad 28.9$ Ref

0.008

4,220

1,525

1,188 28.2 Ref

$\begin{array}{lllll}440 & 28.9 & 1.13 & 0.076 & (0.99-1.29)\end{array}$

$\begin{array}{llllll}195 & 22.5 & 0.83 & 0.045 & (0.70-0.99)\end{array}$

$\begin{array}{llllll}125 & 22.9 & 0.86 & 0.157 & (0.69-1.06)\end{array}$

\section{ACCEPTANCE $(n=3,428)$}

$\mathrm{n} \%$ Ora p IC95\%

$1,570 \quad 50.9 \quad$ Ref

$1,858 \quad 45.6 \quad 0.79<10^{-3} \quad(0.72-0.88)$ $<10-$

3

$3,131 \quad 47.8$

$297 \quad 48.8$

0.650

$990 \quad 44.2 \quad 0.80<10^{-3} \quad(0.72-0.89)$

$2,438 \quad 49.6$ Ref $<10$ -

3

$1,538 \quad 46.0 \quad$ Ref

$\begin{array}{lllll}1,243 & 49.1 & 1.13 & 0.023 & (1.02-1.40)\end{array}$

$\begin{array}{lllll}647 & 50.5 & 1.22 & 0.005 & (1.06-1.40)\end{array}$ 0.008

$\begin{array}{lllll}157 & 41.3 & 0.81 & 0.097 & (0.65-1.00)\end{array}$

$\begin{array}{lllll}610 & 47.8 & 1.06 & 0.409 & (0.93-1.21)\end{array}$

$\begin{array}{llllll}847 & 47.7 & 1.04 & 0.550 & (0.92-1.16)\end{array}$

$\begin{array}{lll}1,814 & 48.7 \text { Ref }\end{array}$ 0.056

$2,051 \quad 48.6 \quad$ Ref

$\begin{array}{lllll}738 & 48.4 & 1.06 & 0.380 & (0.94-1.19)\end{array}$

$\begin{array}{llllll}380 & 43.8 & 0.09 & 0.097 & (0.76-1.02)\end{array}$

$\begin{array}{lllll}259 & 47.4 & 1.00 & 0.948 & (0.84-1.21)\end{array}$

\section{RETURN ( $n=1,948)$}

$\mathrm{n} \%$ Ora p IC95\%

$897 \quad 57.1$ Ref

$\begin{array}{lllll}1,051 & 56.6 & 0.97 & 0.642 & (0.84-1.12)\end{array}$

0.738

$1,766 \quad 56.4 \quad$ Ref

$\begin{array}{lllll}182 & 61.3 & 1.11 & 0.402 & (0.87-1.43)\end{array}$ 0.105

$472 \quad 47.7 \quad 0.65<10^{-3} \quad(0.56-0.76)$

$1,476 \quad 60.5$ Ref

$<10-3$

$928 \quad 60.3$ Ref

$\begin{array}{lllll}709 & 57.0 & 0.94 & 0.421 & (0.80-1.10)\end{array}$

$31148.1 \quad 0.70<10^{-3} \quad(0.58-0.86)$ $<10-3$

$\begin{array}{lllll}96 & 61.2 & 1.30 & 0.143 & (0.92-1.84)\end{array}$

$\begin{array}{lllll}312 & 51.2 & 0.82 & 0.050 & (0.68-1.00)\end{array}$

$\begin{array}{lllll}464 & 54.8 & 0.90 & 0.207 & (0.76-1.06)\end{array}$

$1,076 \quad 59.3$ Ref 0.002

1,188 57.9 Ref

$\begin{array}{llll}440 & 59.6 & 1.18 & 0.072\end{array}$

$\begin{array}{llll}195 & 51.3 & 0.84 & 0.126\end{array}$

$\begin{array}{llll}125 & 48.3 & 0.77 & 0.062\end{array}$

$(0.56-0.76)$

$(0.99-1.41)$

(0.67-1.05) 
Frequenting gay meeting places (with or without sex)

$\begin{array}{lcrrrrr}\text { Often } & 1,974 & 568 & 28.8 & \text { Ref } & & \\ \text { Sometimes } & 3,669 & 1,022 & 27.9 & 0.94 & 0.633 & (0.72-1.22) \\ \text { Never } & 1,515 & 358 & 23.6 & 0.72 & 0.028 & (0.53-0.96) \\ p & & & 0.001 & & & \\ \text { Number of male sex partners in the past } 12 \text { months } & & & & & \\ 2-5 & 2,283 & 552 & 24.2 & \text { Ref } & & \\ 6-10 & 1,918 & 551 & 28.7 & 1.20 & 0.230 & (0.89-1.63) \\ 11-20 & 1,507 & 451 & 29.9 & 1.06 & 0.706 & (0.78-1.45) \\ >20 & 1,450 & 394 & 27.2 & 1.07 & 0.656 & (0.80-1.43) \\ p & & & <10^{-3} & & & \\ \text { Last partner } & & & & & & \\ \text { Steady } & 1,540 & 416 & 27.0 & & & \\ \text { Casual } & 5,618 & 1,532 & 27.3 & & & \\ p & & & 0.841 & & & \\ \text { Protection at last intercourse } & & & & & & \\ \text { No } & 3,156 & 832 & 26.4 & \text { Ref } & & \\ \text { Yes } & 4,002 & 1,116 & 27.9 & 1.01 & 0.820 & 0.91-1.13 \\ p & & & 0.150 & & & \\ \text { Tested for HIV } & & & & & & \\ \text { Several times in the past 12 months } & 1,838 & 508 & 27.6 & 0.86 & 0.045 & (0.74-0.99) \\ \text { Once in the past 12 months } & 1,686 & 507 & 30.1 & \text { Ref } & & \\ \text { At least once, more than 12 months ago } & 2,791 & 733 & 26.3 & 0.87 & 0.042 & (0.76-0.99) \\ \text { Never } & 843 & 200 & 23.7 & 0.78 & 0.012 & (0.64-0.95) \\ p & & & 0.004 & & & \end{array}$

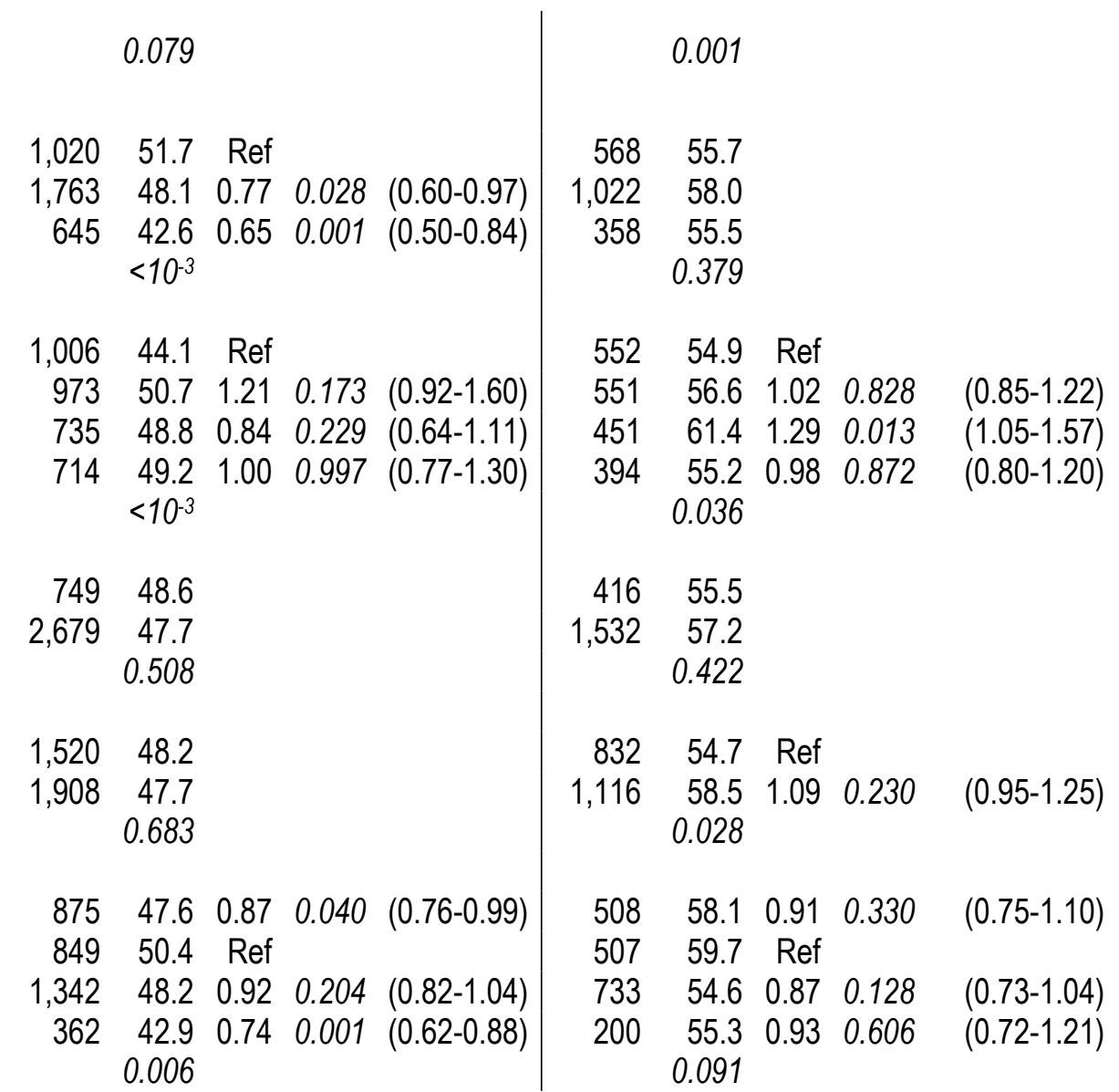


In a multivariate analysis, the acceptance rate was strongly associated with sociodemographic data. It was lower in men aged over 30 years (ORa $=0.79, \mathrm{IC} 95 \%[0.72-0.88]$ vs less than 30 years) and in those who had not attended college (ORa=0.80; IC95\% [0.72-0.89] vs college graduates). However, the acceptance rate was better in men declaring an average (ORa=1.13; IC95\% [1.02-1.40]) or bad financial situation (ORa=1.22; IC95\% [1.06-1.40]) in comparison to those with a good situation.

Considering the socialization patterns in the community, the men who visited gay meeting places signed up for the kit and the program less frequently than the others. The highest difference in the acceptance rate was observed between men who frequently visit gay meeting places (51.7\%) and those who never did (42.6\%, p<10-3) (ORa=0.65; IC95\% [0.50-0.84]).

Acceptance was better in men who had sought HIV screening in the past. Men who had never been tested had a lower acceptance rate than those who were tested once in the past 12 months (ORa=0.74; IC95\% [0.62-0.88]). Nevertheless, those who were tested several times in the past year also accepted the kit less often (ORa=0.87; IC95\% [0.76-0.99]).

Return rate and associated factors.

The return rate varied from $47.7 \%$ to $61.4 \%$ among the subscribers.

In a multivariate analysis, the return rate was strongly associated with sociodemographic data. It was lower for men who had not attended college (ORa: 0.65 ; IC95\% [0.56-0.76] vs college graduates) and for men who reported a difficult financial situation (ORa=0.7; IC95\% [0.580.86]) compared to those with a good situation.

Men with a high number of partners in the past year (between 11 and 20) returned their kit more often than those with less than five partners (ORa=1.29; IC95\% [1.05-1.57]). There was no association with preventive behaviors.

As a result of these associations, the overall participation rate was found to be strongly associated with being aged under 30 years (ORa $=0.66$; IC95\% [0.58-0.75] for men aged 30 years and older) and having a college education (ORa=0.83; IC95\% [0.74-0.92] for men without a college education). No association was made with the perceived financial situation. A lower overall participation was observed in the PACA region.

Never visiting gay meeting places and not being tested for HIV in over a year were associated with a decreased overall participation rate (respectively ORa $=0.72 ; \mathrm{IC} 95 \%$ [0.53-0.76] and ORa=0.78; IC95\% [0.64-0.95]). However, this association is weaker than that observed with sociodemographic data.

\section{Discussion}

Our results show that $47.9 \%$ of eligible men accepted to receive the self-sampling kit, with $56.8 \%$ of them returning at least one of their samples to the laboratory, thus leading to an overall participation rate of $27.2 \%$. More than one out of four eligible MSM completed the selfsampling for HIV and STIs.

Few studies report the overall participation rate as defined in our study. Usually, evaluations focus mainly on the return rate without considering the acceptance rate. However, studies that 
investigate different populations or use different recruitment processes may still be used to discuss our results. In the $\mathrm{SH}: 24$ experiment conducted over a period of 9 months and targeting people aged 16-30 years without consideration of their sexual orientation, the overall participation rate was $37.6 \%(388 / 1,031)$ after 6 weeks [16]. This experiment used a variety of recruitment methods: online as well as advertising displays in university bars and nightclubs and outreach methods. Our internet-only recruitment had a narrower scope but the MemoDepistages program was able to recruit a large number of high-risk MSM $(n=7,158)$ over a short period of time. The main reason for ineligibility was not living in an area of interest. This shows that the targeting worked efficiently and that the program was properly designed for this population.

Among men who were offered to participate in MemoDepistages, nearly half accepted. While the acceptance rate was lower than that found in a phone-administered health study $(82.4 \%$ for MSM [15]), it is consistent with that observed for a Ct screening kit offered to French youths in the Chlamyweb study (around 50\%) [16].

In our study, the recruitment period was 2 months. The return rate of $56.8 \%$ is consistent with the rates observed for different long-term SSK services. For example, in the Dean Street @Home Service, 55.2\% of participants returned their kit during the 2 years of the evaluation [18]. In the evaluation of the Umbrella Health Service, 63.2\% of MSM returned the SSK [7]. Calculated at least 1 year after implementation, this rate may have further improved over time. In the first year of the national UK HIV self-sampling program, the return rate was $52.7 \%$, all populations combined, with the rate increasing to $60.4 \%$ after 3 years [8]. Consequently, the return rate calculated in our study may be seen as a baseline return rate for such a program in France.

In France, men living in a city with more than 50,000 inhabitants are usually tested more often than men from rural areas [20]. With the self-sampling kit, no differences were found according to the size of the place of residence. The online outreach and proposition of the program cancelled out the territorial inequality usually observed in screening. However, a lower overall participation rate has been observed in the Provence Alpes Cote d'Azur region. Our investigations revealed that this region has some specificities in terms of delivery services (different work organisation, more of non- standardized mailbox...). This result highlighted how the service could be impacted with local characteristics.

The acceptance process is crucial in defining the profile of participants, as it was strongly associated with individual sociodemographic characteristics. As previously found, a young age and high school diploma were associated with a better overall participation rate [7, 12]. Men aged under 30 years had a better acceptance rate in our study, which impacts their overall participation, even if they returned the kit at the same rate as older participants. Non-college graduates participated less in the program and also returned their sample less frequently, leading to the highest difference between groups in terms of the overall participation rate ( 9 points).

Similar associations were also found in a self-sampling study in the general population [17]. These characteristics were also associated with screening in the standard health services [4, 21]. Such individuals were more likely to take part in this new screening offer with the SSK. Nevertheless, despite the disappointing low overall participation rate observed in the population who had never been tested for HIV or had not been tested for more than one year, 
the benefit in increasing the testing rate for HIV and STIs using SSK could still be attractive when compared to the traditional system, as previously shown in younger populations [19].

When looking at the behavioral characteristics, participants with 11 to 20 partners during the past year used the SSK more often after receiving it. This behavior corresponds to a global risk perception instead of a reaction to a recent risk, since no difference was observed in the acceptance or return of the SSK for people with and without protection against HIV during their last intercourse. This conclusion is reinforced when considering men's history of HIV testing. MSM who most frequently used the SSK were already familiar with HIV screening and had already been screened at least once during the last year, although the screening needs to be repeated to meet the national health guidelines. If considering the relation of men with gay meeting places, those who frequently visited those venues took advantage from the NGO's outreach and screening offer in those venues. Consequently, they already have a better access to screening and education about screening benefits. They order less, but when they did, they are more willing to return the samples.

Our study has several limitations. First, the campaign was advertised online and focused on providing SSKs for HIV \& STI screening. We therefore did not recruit men who did not use the internet, and it is probable that those who clicked on the advertisement had a greater general interest in STIs. As a result, our sample is a convenience sample, and thus the results cannot be applied to the entire MSM population. As the recruitment only took place over 6 weeks, men who were resistant to change, whether in the form of new products or screening propositions, would not have shown their interest in the program. This short-term recruitment, proposing a new way to get screened, may have led to a selection of early adopters profiles. However, it mimics the design of several long-term interventions developed internationally, whose results could be used to inform policymakers on the potential of such initiatives in France.

Secondly, no information was available to us regarding the difficulties faced during the sampling. The reasons for non-return were not investigated, and we therefore cannot draw on any original data to explain the difference in the return rates between groups. However, qualitative study will investigate keys of the program success at the end of the program.

Finally, return rates were calculated using data available on 30 August 2018. After this date, some SSKs were still being returned. This choice led to a small underestimation of the return rate in our sample and may have slightly impacted the population characteristics.

\section{Conclusion}

The MemoDepistages study reached its main target of MSM frequently exposed to STIs: A high number of partners during the past 12 months and a frequent unprotected last intercourse. With half of them not being test during the last 12 months, this population needed to increase its screening frequency. Results of MemoDepistages regarding SSK used suggest that this approach may succeeded in removing the traditional geographical inequalities associated with screening access [20]. Studies have shown that populations with lower screening rates are those who benefit the most from such interventions in terms of rate increase $[16,19]$. Several factors linked to screening in conventional settings [20] were also found in MemoDepistages, and further analysis on the effect of the intervention are needed to conclude on its global impact. Following this initial screening, participants will be able to choose whether they prefer to use the SSK or another screening option for routine quarterly testing over 18 months. An 
observation of the various screening iterations will allow us to better understand how the SSK completes the current French screening strategies. 


\section{Key messages}

- STI Self sampling kit (SSK) are more used when people already have a recent HIV screening experience

- Several factors linked to screening in conventional settings were also found associated with SSK

- It contribute to address the unequal access to testing across the country

\section{Fundings}

This work was supported by the Agence Nationale de Recherches sur le Sida et les Hépatites Virales (ANRS) [grant number ECTZ47249]. 


\section{References}

1. Marty, L., et al., Revealing geographical and population heterogeneity in HIV incidence, undiagnosed HIV prevalence and time to diagnosis to improve prevention and care: estimates for France. Journal of the International AIDS Society, 2018. 21(3): p. e25100.

2. Haute autorité de santé, Réévaluation de la stratégie de dépistagede l'infection à VIH en France. 2017, Haute autorité de santé: Saint Denis.

3. Lydie, N., L. Duchesne, and A. Velter, Qui sont les utilisateurs de l'autotest vih parmi les hommes ayant des rapports sexuels avec des hommes en france ? Résultats de l'enquête rapport au sexe 2017. Bulletin epidémiologique hebdomadaire, 2018. 40-41: p. 799-804.

4. Velter, A., L. Duchesne, and N. Lydie, [Increase in frequency of repeat HIV testing among men who Have sex with men in France between 2017 and 2019. Results from the Rapport au Sexe Survey]. Bulletin epidémiologique hebdomadaire, 2019. 31-32: p. 9.

5. Section MST/SIDA, Dépistages de MST/IST. Reccomandations diagnostiques et thérapeutiques pour les Maladies sexuellement transmissibles. Société Française de dermatologie. 2016

6. Duchesne, L., N. Lydie, A. Velter, Increase in the overall level of protected anal sex in men who have sex with men in France: results from the repeated cross-sectional survey Rapport au Sexe, France, 2017-2019. AIDS Care. 2020:1-8

7. Manavi, K. and J. Hodson, Observational study of factors associated with return of home sampling kits for sexually transmitted infections requested online in the UK. BMJ open, 2017. 7(10): p. e017978.

8. Harb, A., L. Logan, and L. Guerra, National HIV self-sampling service. 2019, Public Health England: London.

9. Morris, S.R., et al., Evaluation of an HIV nucleic acid testing program with automated Internet and voicemail systems to deliver results. Annals of internal medicine, 2010. 152(12): p. 778785.

10. Gilbert, M., et al., Factors associated with intention to use internet-based testing for sexually transmitted infections among men who have sex with men. Journal of medical Internet research, 2013. 15(11).

11. Fisher, M., et al., Home Sampling for Sexually Transmitted Infections and HIV in Men Who Have Sex with Men: A Prospective Observational Study. PloS one, 2015. 10(4): p. e0120810.

12. Brown, L., et al., Using behavioural insights to increase HIV self-sampling kit returns: a randomized controlled text message trial to improve England's HIV self-sampling service. HIV medicine, 2018. 19(9): p. 585-596.

13. Gaydos, C., et al., P48 Yearly trends for the internet recruitment program, http://www. iwantthekit. org-what happened to the STI prevalence? Sexually transmitted infections, 2012. 88(Suppl 1): p. A26-A26.

14. Hoyos, J., et al., Knowledge, actual and potential use of HIV self-sampling testing kits among MSM recruited in eight European countries. HIV medicine, 2018. 19: p. 27-33.

15. Miners, A., et al., Preferences for HIV testing services among men who have sex with men in the UK: A discrete choice experiment. PLoS medicine, 2019. 16(4): p. e1002779.

16. Wilson, E., et al., Internet-accessed sexually transmitted infection (e-STI) testing and results service: A randomised, single-blind, controlled trial. PLoS medicine, 2017. 14(12): p. e1002479.

17. Rahib, D., et al., [Acceptability and feasibility of home self-sampling for HIV, HBV and HCV testing in the general population in France in 2016: BaroTest study]. Bulletin epidémiologique hebdomadaire, 2019. 24-25: p. 13.

18. Elliot, E., et al., Identifying undiagnosed HIV in men who have sex with men (MSM) by offering HIV home sampling via online gay social media: a service evaluation. Sexually transmitted infections, 2016: p. sextrans-2015-052090.

19. Kersaudy-Rahib, D., et al., Chlamyweb Study II: a randomised controlled trial (RCT) of an online offer of home-based Chlamydia trachomatis sampling in France. Sex Transm Infect, 2017. 93(3): p. 188-195. 
20. Velter, A., et al., Pratiques de dépistage VIH des hommes ayant des rapports sexuels avec des hommes. Apports de l'Enquête presse gays et lesbiennes 2011 [HIV Testing Practices among Men Who Have Sex with Men. Results of the Gay and Lesbian Survey 2011 France]. Bulletin Epidemiologique Hebdomaire, 2014. 32(33): p. 541-547.

21. Bruyand, M., et al., [Opinions and practices of persons aged from 18 to 75 years in mainland France regarding HIV testing in 2016]. Bulletin epidémiologique hebdomadaire, 2019. 31-32: p. 9. 